\title{
Effect of removal of the ovarian bursa of the rat on infundibular retrieval and subsequent development of ovulated oocytes
}

\author{
B. C. Vanderhyden, A. Rouleau and D. T. Armstrong \\ M.R.C. Group in Reproductive Biology, and Departments of Physiology and Obstetrics and \\ Gynaecology, University of Western Ontario, London, Ontario, Canada N6A 5 A5
}

\begin{abstract}
Summary. The ovarian bursa was peeled from around one ovary of each rat and the rats were killed 1, 2, 3, 4 and 5 weeks later. The proportion of rats that maintained a bursa-free ovary did not change over the 5-week period (80-89\%). Ovulation from the peeled ovary occurred in all rats but oocytes $(1-4)$ were found in the ipsilateral oviduct in only $18 \%$ of the rats. The presence of oocytes in the oviduct was normally associated with some degree of re-encapsulation of the ovary. In another experiment rats were mated within 1 week of removal of the bursa from around the ovary. Unilateral pregnancy resulted in $92 \%$ of the rats. In a third experiment fertilized oocytes from mated donor rats were transferred into the oviduct next to the peeled ovary in 15 mated recipients. Of 85 zygotes transferred, 51 survived to be viable fetuses on Day 20. A single fetus developing from an endogenous oocyte was found in the transfer uterine horn in only one rat.

This preparation may be useful in studies which attempt to determine the viability, of oocytes that have undergone various manipulations in vivo or in vitro.
\end{abstract}

\section{Introduction}

In-vitro fertilization and embryo transfer are techniques currently being used for the treatment of human infertility. Despite the relative success of in-vitro fertilization, the development of these embryos has been less than optimal, with over $80 \%$ of transfers failing to establish full-term pregnancies (Grobstein, Flower \& Mendeloff, 1983). Most investigations into the viability of in-vitro fertilized rat oocytes have involved transfer into pseudopregnant recipients (Toyoda \& Chang, 1974; Shalgi, 1984). Pseudopregnancy is commonly induced by electrical stimulation of the cervix or by mating with a vasectomized male. With these techniques, however, ovulated oocytes will be present in the oviduct and may interfere with investigations into early embryonic development of transferred oocytes. Using mated recipients, some investigators have used the genetic marker of eye colour to distinguish between endogenous and transferred embryos (Noyes, 1952; Walton \& Armstrong, 1983), but this technique is useful only when examining development to the later stages of gestation, when pigmentation is at detectable levels. To study embryonic development during early gestation, it was necessary to develop a model in which endogenous embryos could be distinguished from transferred embryos, or in which transferred embryos could remain isolated from endogenous embryos.

To develop a model for in-vivo fertilization of transferred oocytes, Shalgi, Dekel \& Kraicer (1979) removed the ovary at the time of transfer into the ipsilateral oviduct. When this technique was performed before ovulation had occurred in the recipient rat, the oviduct could contain only transferred oocytes. Removal of the ovary has uncertain effects on the subsequent pregnancy and can cause bleeding that is sometimes difficult to control. The purpose of this study was to develop a less damaging, but equally effective, method to produce unilateral pregnancy. 
In the rat and the mouse, encapsulation of the ovary by the bursa ovarica is almost complete (Robinson, 1887; Alden, 1942; Wimsatt \& Waldo, 1945), unlike in women, in which the ovarian bursa is absent or nearly so. In the rat, destruction or opening of the bursa before mating has been shown to be of moderate success in limiting the number of fetuses found in the ipsilateral uterine horn (Neugebauer, 1935; Kelly, 1939). In the present study this procedure was modified and its usefulness for the study of transferred oocytes or embryos was examined.

\section{Materials and Methods}

Immature and mature female Sprague-Dawley rats, mature male Sprague-Dawley rats and mature female Long-Evans rats were obtained from Charles River Canada Inc., St Constant, Quebec. They were housed in air-conditioned quarters with free access to food and water. Lighting was provided for $14 \mathrm{~h}$ daily.

Experiment 1. Adult Long-Evans rats were anaesthetized by intraperitoneal injection of tribromoethanol solution $(2 \%, 0.01 \mathrm{mg} / \mathrm{g}$ body wt) and the bursa was peeled back from around the left ovary of each rat. The bursa around the right ovary was left intact and this side was used as a control. The left ovary was exposed through a flank incision and was drawn out by pulling on the fat pad. After lifting the bursa away from the ovary with a pair of fine forceps (Fig. 1a), a small hole was made in the bursa using a pair of iridectomy scissors, care being taken to avoid any bleeding (Figs $1 \mathrm{~b} \& 1 \mathrm{c}$ ). It was presumed that, with a small hole, the bursa would be less likely to slip back on the ovary. The ovary was gently manipulated through the hole with fine forceps until the entire ovary was exposed (Figs 1d-1f). The ovary was then replaced in the abdominal cavity.

At 2 days after the operation (Day - 4), the cycles of about one-fifth of the rats were synchronized with an LHRH agonist (des-Gly ${ }^{10}$, D-Ala ${ }^{6}$, L-ProNHEt ${ }^{9}$ LHRH; Sigma, St Louis, MO, U.S.A.) using a method described previously (Walton \& Armstrong, 1983). With this method, ovulation occurs in the early morning of Day 1 . On the morning of Day 1 (1 week after the operation), vaginal smears were taken and only rats in oestrus were subsequently killed. The bursa-free ovary was examined for adhesions or possible re-encapsulation of the ovary. Ovaries and oviducts from both sides were removed. Corpora lutea associated with ruptured follicles were counted. The oocytes were collected by inserting a 30 -gauge needle into the infundibulum of the oviduct and flushing with $0.2 \mathrm{ml}$ Dulbecco's phosphate-buffered saline (DPBS; Gibco Laboratories, Grand Island, New York). The synchronization of rat cycles and subsequent killing during oestrus were repeated so that 9-16 rats were killed each week for 5 weeks from the day of bursa peeling.

Experiment 2. The bursa was peeled from around the left ovary of 35 mature Sprague-Dawley rats and 19 mature Long-Evans rats, as described for Exp. 1. After 3-4 days for recovery, the animals were caged with males for 5 days and allowed to mate. The female rats were killed 13 days later and the number of fetuses in each uterine horn was counted. The bursa-free ovary was examined for adhesions or re-encapsulation, and the number of corpora lutea was counted. Only rats with fetuses in the control horn were used in the analysis.

Fig. 1. A series of photographs showing the technique for peeling the bursa from around the rat ovary. (a) The bursa is lifted away from the ovary with a pair of fine forceps. (b) Using iridectomy scissors, a small hole is made between blood vessels of the bursal membrane. (c) Fine forceps are used to indicate the edges of the small hole that has been made in the bursa. (d) The ovary is gently manipulated through the small hole. In this photograph the upper portion of the ovary is already free of the bursal covering. (e, f) Due to its elastic properties, the bursa remains as an intact covering around the oviduct and, in addition, now acts as a barrier between the infundibulum of the oviduct (indicated by the arrow in $f$ ) and the ovary. 

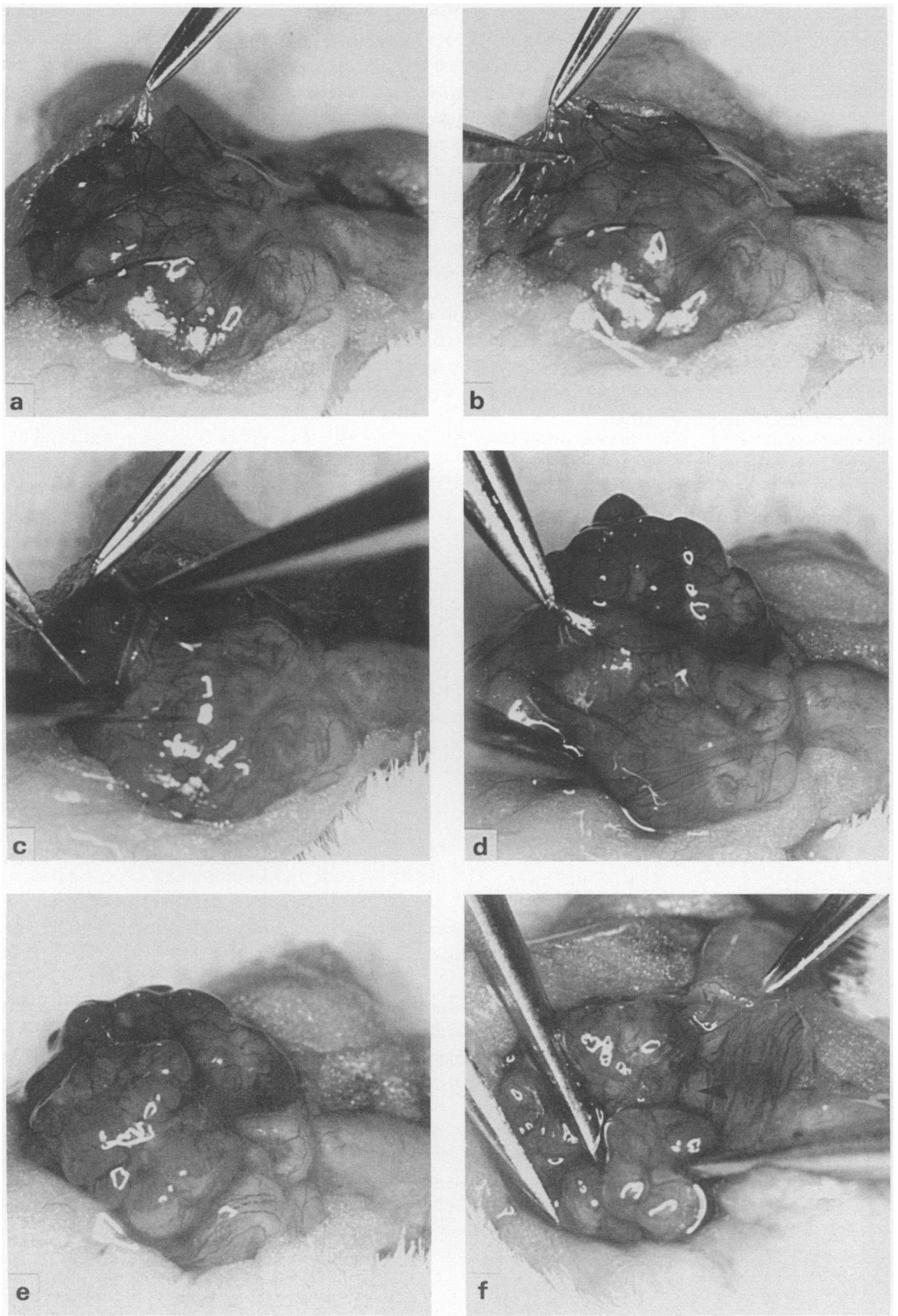
Experiment 3. Immature female Sprague-Dawley (albino) rats were treated on Day -2 with 4 i.u. PMSG to induce follicular growth (Day $1=$ day of ovulation). On or within 2 weeks before Day -3 , the bursa was peeled from around the left ovary of each Long-Evans (pigmented) rat. The Sprague-Dawley and Long-Evans rats were caged with males of proven fertility from $20: 00 \mathrm{~h}$ on Day 0 to $03: 00 \mathrm{~h}$ on Day 1, with copulatory plugs or spermatozoa in the vaginal smears taken as evidence of insemination. The immature rats were killed at 20:00 $\mathrm{h}$ on Day 1 and the oviducts were flushed with DPBS. Oocytes with two pronuclei and one sperm tail were transferred immediately into the left oviduct of the mated recipient (Long-Evans) rats (Vanderhyden, Rouleau, Walton \& Armstrong, 1986). The recipient rats were killed on Day 20 and the fetuses in each uterine horn were counted and weighed. In the transfer horn (i.e. the uterine horn associated with the peeled ovary) the fetuses were identified as pigmented (endogenous) or albino (transferred).

Statistical analyses. The proportions of rats in each group with no evidence of re-encapsulation were compared using $\chi^{2}$ analyses with Yates' correction. In Exp. 2, the numbers of corpora lutea on the control and peeled ovaries were compared by using a Student's two-tailed $t$ test (Steel \& Torrie, 1980). Differences in mean fetal and placental weights between the control and transfer sides in Exp. 3 were similarly compared.

\section{Results}

\section{Experiment 1}

The average number of corpora lutea and ovulated oocytes on the control and the peeled sides of the rats are summarized in Table 1 . The degree of re-encapsulation of the peeled ovary is also indicated. On the control side the average number of corpora lutea was not significantly different from the average number of ovulated oocytes $(P>0 \cdot 1)$. In contrast, although all the rats ovulated from the peeled ovary, as indicated by the presence of corpora lutea, only $18 \%$ contained oocytes in the ipsilateral oviduct. In the rats in which ovulated oocytes were found on the operated side, the average number of oocytes $(2 \cdot 0 \pm 0.4)$ was significantly less than the average number of corpora lutea $(6.5 \pm 1 \cdot 1)$ on that side $(P<0.01)$. In most cases presence of oocytes on the operated side was associated with partial or complete re-encapsulation of the ovary. In 4 rats (out of a total of 60 operated animals) one oocyte was found in the oviduct when the ipsilateral ovary appeared to be completely free of the bursa (Table 2).

Complete re-encapsulation of the ovary was possible within 2 weeks of the removal of the bursa from around the ovary. The percentage of rats with the ovary still completely exposed did not change significantly over the 5 -week period $(80-89 \%)(P>0 \cdot 1)$. There was a statistically significant increase in the number of corpora lutea between Weeks 1 and 5 in both the control and peeled ovaries $(P<0.05)$.

Table 1. Average number of corpora lutea and oviducal oocytes in rats $1-5$ weeks after unilateral peeling of the bursa

\begin{tabular}{|c|c|c|c|c|c|c|c|c|c|}
\hline \multirow{3}{*}{$\begin{array}{l}\text { Time } \\
\text { after } \\
\text { bursa } \\
\text { peeling } \\
\text { (weeks) }\end{array}$} & \multirow[b]{3}{*}{$\begin{array}{c}\text { No. of } \\
\text { rats }\end{array}$} & \multirow{2}{*}{\multicolumn{2}{|c|}{ Control side }} & \multicolumn{3}{|c|}{ Peeled side } & \multirow{2}{*}{\multicolumn{3}{|c|}{$\begin{array}{l}\text { Re-encapsulation } \\
\text { of ovary }\end{array}$}} \\
\hline & & & & \multirow{2}{*}{$\begin{array}{c}\text { Average } \\
\text { no.of } \\
\text { CL }\end{array}$} & \multirow{2}{*}{$\begin{array}{l}\text { No. of } \\
\text { rats with } \\
\text { oocytes }\end{array}$} & \multirow{2}{*}{$\begin{array}{l}\text { Average no. } \\
\text { of oocytes/ } \\
\text { rat with } \\
\text { oocytes }\end{array}$} & & & \\
\hline & & $\begin{array}{l}\text { Average } \\
\text { no. of } \\
\text { CL }\end{array}$ & $\begin{array}{l}\text { Average } \\
\text { no.of } \\
\text { oocytes }\end{array}$ & & & & None & Partial & Complete \\
\hline 1 & 10 & $6 \cdot 1$ & 5.6 & 5.5 & 0 & 0 & 8 & 2 & 0 \\
\hline 2 & 15 & $6 \cdot 2$ & 6.6 & $4 \cdot 2$ & 3 & 2 & 12 & 2 & 1 \\
\hline 3 & 10 & 6.4 & $6 \cdot 7$ & 4.6 & 3 & 1.7 & 8 & 1 & 1 \\
\hline 4 & 16 & 9.5 & 8.4 & $8 \cdot 1$ & 4 & 1.8 & 14 & 0 & 2 \\
\hline 5 & 9 & 8.0 & $7 \cdot 4$ & 8.2 & 1 & 4 & 8 & 0 & 1 \\
\hline
\end{tabular}


Table 2. Degree of re-encapsulation of the ovary and the presence of oocytes in oviducts ipsilateral to the peeled ovary

\begin{tabular}{lcccc}
\hline $\begin{array}{l}\text { Degree of ovary } \\
\text { re-encapsulation }\end{array}$ & $\begin{array}{c}\text { No. of } \\
\text { rats }\end{array}$ & $\begin{array}{c}\text { No. of rats } \\
\text { with oocytes }\end{array}$ & $\begin{array}{c}\text { No. of } \\
\text { oocytes }\end{array}$ & $\begin{array}{c}\text { No. of oocytes } \\
\text { per rat }\end{array}$ \\
\hline None & 50 & 4 & 4 & 1 \\
Partial & 5 & 2 & 2 & 1 \\
Complete & 5 & 5 & 16 & $3 \cdot 2$ \\
\hline
\end{tabular}

\section{Experiment 2}

The degree of re-encapsulation of the ovary on the operated side and the presence of fetuses in the ipsilateral uterine horn are summarized in Table 3. The presence of fetuses in the uterine horn of the peeled ovary was normally associated with complete re-encapsulation of the ovary. In only one case, fetuses (3) were present in the uterine horn of a rat in which the peeled ovary still appeared to be completely exposed. In the Sprague-Dawley rats, ovulation on the operated side was verified by the presence of corpora lutea, and the average number of corpora lutea on that side $(5.5 \pm 0.4)$ was not significantly different from the number on the control side $(5 \cdot 2 \pm 0.4)(P>0 \cdot 1)$.

\section{Experiment 3}

The recovery of viable fetuses after transfer of 85 in-vivo fertilized oocytes was $60 \%$ (Table 4 ). In all cases but one, the transfer horn contained only fetuses with non-pigmented eyes, indicating the albino donor as the source. In one case a single black-eyed fetus was found in the transfer horn, along with the non-pigmented fetuses. In all rats the control horn contained only fetuses with pigmented eyes.

There was no significant difference between the control and transfer sides with respect to fetal or placental weights $(P>0 \cdot 1)$.

Table 3. Numbers of fetuses surviving in each uterine horn after unilateral peeling of the ovarian bursa

\begin{tabular}{|c|c|c|c|c|c|c|c|c|}
\hline \multirow{3}{*}{$\begin{array}{l}\text { Strain } \\
\text { of rat }\end{array}$} & \multirow{3}{*}{$\begin{array}{l}\text { No. of } \\
\text { rats }\end{array}$} & \multicolumn{2}{|c|}{ Control side } & \multicolumn{2}{|c|}{ Peeled side } & & & \\
\hline & & \multirow{2}{*}{$\begin{array}{l}\text { No. of } \\
\text { rats with } \\
\text { fetuses }\end{array}$} & \multirow{2}{*}{$\begin{array}{c}\text { Average } \\
\text { no. of } \\
\text { fetuses }\end{array}$} & \multirow{2}{*}{$\begin{array}{l}\text { No. of } \\
\text { rats with } \\
\text { fetuses }\end{array}$} & \multirow{2}{*}{$\begin{array}{l}\text { Average } \\
\text { no. of } \\
\text { fetuses }\end{array}$} & \multicolumn{3}{|c|}{ Re-encapsulation of ovary } \\
\hline & & & & & & None & Partial & Complete \\
\hline $\begin{array}{l}\text { Sprague- } \\
\text { Dawley }\end{array}$ & 32 & 32 & $5 \cdot 3$ & 3 & 2 & 27 & 1 & 4 \\
\hline $\begin{array}{l}\text { Long- } \\
\text { Evans }\end{array}$ & 19 & 19 & 6.8 & 1 & 3 & 14 & 3 & 2 \\
\hline
\end{tabular}

Table 4. Percentage of transferred zygotes recovered as viable fetuses and mean fetal and placental weights 20 days after zygote transfer

\begin{tabular}{|c|c|c|c|c|c|}
\hline Uterine horn & $\begin{array}{l}\text { Embryos } \\
\text { recovered/ } \\
\text { transferred }\end{array}$ & $\begin{array}{l}\text { No. of } \\
\text { rats with } \\
\text { fetuses }\end{array}$ & $\begin{array}{l}\text { Source of } \\
\text { fetuses }\end{array}$ & $\begin{array}{c}\text { Mean } \pm \text { s.e.m. } \\
\text { fetal wt } \\
\text { (g) }\end{array}$ & $\begin{array}{l}\text { Mean } \pm \text { s.e.m. } \\
\text { placental wt } \\
(\mathrm{mg})\end{array}$ \\
\hline $\begin{array}{l}\text { Control } \\
\text { Transfer }\end{array}$ & $51 / 85(60 \%)$ & $\begin{array}{r}15 \\
15 \\
1\end{array}$ & $\begin{array}{l}\text { Endogenous } \\
\text { Transferred } \\
\text { Endogenous }\end{array}$ & $\begin{array}{l}1.86 \pm 0.08 \\
1.79 \pm 0.09 \\
1.98\end{array}$ & $\begin{array}{l}466 \pm 21 \\
451 \pm 23 \\
463\end{array}$ \\
\hline
\end{tabular}




\section{Discussion}

Early experiments by Kelly (1939) and Neugebauer (1935) indicated that opening the ovarian bursa in the albino rat distinctly lessens fecundity on the operated side: $44 \%$ of the rats studied by Kelly (1939) and $65 \%$ of those studied by Neugebauer (1935) were unilaterally pregnant. This figure has been increased up to $93 \%$ using the modifications of the procedure described here. The use of this preparation as a recipient for transferred oocytes of various origins should be considered.

Our technique for peeling the bursa has met with some success with regards to maintaining a bursa-free ovary. In his experiments, Kelly (1939) 'pulled open (the bursa) with forceps' and 2 weeks later found complete resacculation of the ovary in $57 \%$ of his animals, with partial resacculation in $16 \%$. It is not surprising then that he should find fetuses on the bursa-peeled side in $56 \%$ of the animals. A possibly more refined technique of bursa peeling was used in the present experiments with minimal, if any, bleeding. By passing the ovary through a small opening, this method had two major advantages. First, the elastic properties of the bursa made it difficult for the ovary to slip back into the bursa after peeling. Secondly, by peeling the bursa from around the ovary, the bursa was consequently in a position to cover the infundibulum of the oviduct, further inhibiting any ovulated oocytes from entering the oviduct. During the 5 weeks of Exp. 1, complete reencapsulation of the ovary occurred in $8 \%$ of the rats and partial re-encapsulation in another $8 \%$ of the animals. Oocytes were found in oviducts next to the peeled ovary in $18 \%$ of the animals. When the animals were used within 2 weeks of the bursa peeling (Exps $2 \& 3$ ), 12\% showed complete re-encapsulation and $8 \%$ showed partial re-encapsulation of the ovary, but only $8 \%$ of the animals had fetuses in the uterine horn ipsilateral to the peeled ovary.

In Exp. 1, the reasons for the increase in the number of corpora lutea between Weeks 1 and 5 both in the control and peeled ovaries are not yet known.

The presence of oocytes in the oviduct ipsilateral to the bursa-peeled ovary did not always occur in rats with complete resacculation. On four occasions oocytes were found in the oviduct next to an ovary that was still completely exposed. These results agree with those of Neugebauer (1935) who concluded that the ovarian bursa is not entirely indispensable for egg transport, but bilateral pregnancy rarely occurs after unilateral bursa peeling.

The results of these experiments indicate that this preparation could be used to produce unilateral pregnancy with only a small margin of error $(<8 \%)$. This error may be further reduced by excluding animals in which the peeled bursa has completely re-encapsulated the ovary. The surgical technique appears to have no effect on the ability of that ovary to ovulate or on the ability of zygotes to develop into viable fetuses in the ipsilateral uterine horn.

\section{References}

Alden, R.H. (1942) The periovarial sac in the albino rat. Anat. Rec. 83, $421-435$.

Grobstein, C., Flower, M. \& Mendelofi, J. (1983) External human fertilization: An evaluation of policy. Science, N. Y. 222, 127-133.

Kelly, G.L. (1939) Effect of opening the ovarian bursa on fecundity in the albino rat. Anat. Rec. 73, 401-405.

Neugebauer, C. (1935) L'influence de la capsule ovarienne sur la fecondité de la rate blanche. C. r. Séanc. Ass. Anat. 30, 400-407.

Noyes, R.W. (1952) Fertilization of follicular ova. Fert. Steril. 3, 1-12.

Robinson, A. (1887) On the position and peritoneal relations of the mammalian ovary. J. Anat. Physiol. 21, 169-179.
Shalgi, R. (1984) Developmental capacity of rat embryos produced by in vivo or in vitro fertilization. Gamete Res. 10, 77-82.

Shalgi, R., Dekel, N. \& Kraicer, P.F. (1979) The effect of LH on the fertilizability and developmental capacity of rat oocytes matured in vitro. J. Reprod. Fert. 55, 429-435.

Steel, R.G.D. \& Torrie, J.H. (1980) Principles and Procedures of Statistics. McGraw-Hill, Inc., New York.

Toyoda, Y. \& Chang, M.C. (1974) Fertilization of rat eggs in vitro by epididymal spermatozoa and the development of eggs following transfer. J. Reprod. Fert. 36, 9-22.

Vanderhyden, B.C., Rouleau, A., Walton, E.A. \& Armstrong, D.T. (1986) Increased mortality during 
early embryonic development after in-vitro fertilization of rat oocytes. J. Reprod. Fert. 77, 401-409.

Walton, E.A. \& Armstrong, D.T. (1983) Oocyte normality after superovulation in immature rats. $J$. Reprod. Fert. 67, 309-314.
Wimsatt, W.A. \& Waldo, C.M. (1945) The normal occurrence of a peritoneal opening in the bursa ovarii of the mouse. Anat. Rec. 93, 47-53.

Received 13 January 1986 